\title{
PENGELOLAAN PRAKTIK KERJA INDUSTRI DI SEKOLAH MENENGAH KEJURUAN MUHAMMADIYAH 1 SUKOHARJO
}

\author{
Sunardi \\ Guru SMK Negeri 2 Sukoharjo \\ Jl. Raya Begajah-Sukoharjo, Telp (0271) 591588, 081556557938 \\ sunardiabdillah@yahoo.co.id
}

\begin{abstract}
The purpose of this study is (1). Describing the characteristics of industrial planning workpractices in SMKMuhammadiyah 1 Sukoharjo, (2). Describing the characteristics of the implementation of the industrial working practices in SMK Muhammadiyah 1 Sukoharjo, (3). Describing the characteristics of the industrial working practices votes in SMK Muhammadiyah 1 Sukoharjo. The research is a qualitative research with descriptive design. Sources in the research is the principal, vice-principal, the chairman of the working group prakerin, head of program membership, earning of teachers and industry leaders. Methods of data collection are observation, interview, and documentation. Analysis of data using an interactive model. The results of the study are (1) .Perencanaan industry work practices include: mapping industry, prakerin program, prakerin time, debriefing prakerin, and the establishment of a tutor, (2) .Pelaksanaan industry work practices include organizing, prakerin student submissions to the industry, monitoring students prakerin and withdrawal prakerin students to school. (3). Assessment practices industry work there are two stages, namely assessments by tutors industry and counselors School with a parameter value of the industry (IN) is weighted 60\%, the value of the journal prakerin (JP) is weighted 10\%, the value of the oral exam (UL) is weighted $20 \%$, and the value of the report $(L P)$ is weighted $10 \%$. So that the total value of the results prakerin students are: $0.6(I N)+0.1(J P)+0.2(L P)+0.1(L P)$.
\end{abstract}

Keywords: management, employment practices industry, SMK

\begin{abstract}
ABSTRAK
Tujuan penelitian ini adalah (1). Mendeskripsikan karakteristik perencanaan prakerin di SMK Muhammadiyah 1 Sukoharjo, (2). Mendiskripsikan karakteristik pelaksanaan Prakerin di SMK Muhammadiyah 1 Sukoharjo, (3). Mendiskripsikan karakteristik penilaian Prakerin di SMK Muhammadiyah 1 Sukoharjo. Jenis penelitian ini adalah penelitian kualitatif dengan desain diskriptif. Nara sumber dalam penelitian adalah kepala sekolah, wakil kepala sekolah, ketua pokja prakerin, kepala program keahlian, guru produktif dan pimpinan industri. Metode pengumpulan data adalah observasi, wawancara mendalam, dan dokumentasi. Analisis data menggunakan model interaktif. Hasil penelitian adalah (1).Perencanaan prakerin meliputi : pemetaan industri, program prakerin, waktu prakerin, pembekalan prakerin, dan penetapan
\end{abstract}


guru pembimbing, (2).Pelaksanaan prakerin meliputi pengorganisasian, penyerahan siswa prakerin ke industri, monitoring siswa prakerin, dan penarikan siswa prakerin ke Sekolah. (3). Penilaian prakerin ada dua tahap, yaitu penilaian oleh pembimbing industri dan pembimbing Sekolah dengan parameter nilai dari industri (IN) diberi bobot $60 \%$, nilai jurnal prakerin (JP) diberi bobot $10 \%$, nilai ujian lisan (UL) diberi bobot $20 \%$, dan nilai laporan (LP) diberi bobot $10 \%$. Sehingga nilai total hasil prakerin siswa adalah : 0,6 (IN) + 0,1(JP) + 0,2 (LP) +0,1 (LP).

Kata Kunci : pengelolaan, praktik kerja industri, SMK

\section{PENDAHULUAN}

Seiring dengan berkembangnya peradaban dunia dan era globalisasi, kompleksnya masalah kehidupan menuntut sumber daya manusia yang handal dan mampu berkompetisi. Pada akhir tahun 2015 Masyarakat Ekonomi Asean (MEA) resmi akan dimulai secara bertahap, Asean sepakat untuk menghilangkan semua peraturan non tarif barrier dan mengimplementasikannya secara menyeluruh di tahun 2020. Kelak dalam masyarakat ini perdagangan barang, jasa, investasi, modal, dan tenaga kerja ahli akan dibebaskan. Waktu untuk mempersiapkan diri untuk memasuki era tersebut sangat pendek, terutama mempersiapkan sumber daya manusia yang unggul. Faktor utama yang menentukan mampu tidaknya bersaing dengan negara lain adalah sumber daya manusia yang memiliki ilmu pengetahuan dan teknologi serta mampu menghasilkan produk yang unggul. Karena itu, penyiapan sumber daya manusia harus dilaksanakan dengan sungguh-sunguh dan terencana dengan baik.

Salah satu upaya yang dilakukan adalah dengan pendidikan dan pelatihan yang sudah dilaksanakan di Sekolah Menengah Kejuruan saat ini. Sekolah Menengah Kejuruan menurut Undang-Undang No.20 tentang Sistem Pendidikan Nasional tahun 2003 Pasal 15 dijelaskan bahwa: "Pendidikan kejuruan merupakan pendidikan yang mempersiapkan peserta didik untuk dapat bekerja dalam bidang tertentu". Lebih spesifik dijelaskan di Peraturan Pemerintah No.19 tahun 2005 tentang standar nasional pendidikan yang menyebutkan target pendidikan menengah yaitu : pendidikan menengah kejuruan adalah pendidikan pada jenjang pendidikan yang mengutamakan pengembangan kemampuan siswa untuk jenis pekerjaan tertentu, karena itu pendidikan kejuruan harus selalu dekat dengan dunia kerja atau industri.

Orientasi tujuan pendidikan kejuruan pada prinsipnya untuk mendukung 3 pilar kebijakan pendidikan nasional, yaitu: (1) membekali ketrampilan dan penguasaan kompetensi tamatan sesuai dengan kebutuhan pasar kerja, yaitu untuk memenuhi kebutuhan tenaga kerja tingkat lokal, regional, nasional maupun global. (2) membekali ketrampilan dan penguasaan kompetensi serta kemampuan berwirausaha untuk menjadi tenaga mandiri, menciptakan lapangan kerja dan wirausaha unggul (interpreneur). (3) membekali ketrampilan dan penguasaan kompetensi serta kemampuan akademis untuk menyiapkan tamatan melanjutkan kejenjang yang lebih tinggi.

Pembaharuan penyelenggaraan pendidikan SMK dimulai sejak dilaksanakan Pendidikan Sistem Ganda (PSG) tahun 1999, selanjutnya disebut dengan Praktik Kerja Industri (Prakerin), yang dilengkapi dengan sejumlah perangkat pelaksanaannya. Dalam perkembangannya 
pelaksanaan prakerin dimantapkan dengan menggunakan acuan yang lebih mendasar yaitu yang tertulis dalam buku "Ketrampilan Menjelang 2020 untuk Era Global” yang disusun oleh satuan tugas pengembangan pendidikan dan pelatihan kejuruan di Indonesia, Departemen Pendidikan dan Kebudayaan (1997). Kemudian, penyelenggaraan Prakerin dibakukan dalam keputusan Menteri Pendidikan dan Kebudayaan R.I. Nomor 323/U/1997 tentang Praktik Kerja Industri pada Sekolah Menengah Kejuruan tanggal 31 Desember 1997, yang memuat komponen-komponen yang diperlukan dalam penyelengaraan prakerin.

Penyelenggaraan kegiatan praktik kerja industri (Prakerin), agar sesuai dengan harapan penyelenggaraanpendidikankejuruan, makadalamimplementasinyaharus “diadministrasikan" atau dikelola dengan baik. Pengelolaan adalah sebuah proses perencanaan, pengorganisasian, pengordinasian, dan pengontrolan sumber daya untuk mencapai sasaran secara efektif dan efisien, (Ridhotullah, 2015 : 1). Sesuai dengan Permendiknas nomor 19 tahun 2007 tentang: Standar Pengelolaan Pendidikan oleh Satuan Pendidikan Dasar dan Menengah, yang meliputi: (1) Perencanaan Program; (2) Pelaksanaan Rencana Kerja; (3) Pengawasan atau Evaluasi. Praktik kerja industri adalah suatu cara menyelenggarakan pendidikan dan pelatihan kejuruan khususnya pada Sekolah Menengah Kejuruan (SMK) yang memadukan kegiatan belajar di sekolah dan kegiatan belajar melalui bekerja langsung pada bidang serta suasana yang sesungguhnya dan relevan di lapangan kerja/dunia usaha dan atau dunia industri dengan harapan terjadi Link and Macth atau keterkaitan dan kesepadanan antara sekolah dengan dunia industri. Mengingat keterbatasan dari pihak industri dalam menerima siswa prakerin, maka pelaksanaannya dilakukan secara bertahap dalam bentuk kelompok-kelompok kecil dan tersebar di beberapa industri yang ada di wilayah Surakarta.

Kondisi objektif yang dapat kita amati tentang sistem pendidikan kejuruan pada umumnya banyak yang hanya mengejar target kelulusan $100 \%$ dan cenderung melupakan DU/DI sebagai salah satu "user" tamatan SMK. Dunia pendidikan kejuruan belum berfikir apakah tamatan SMK dapat bekerja sesuai dengan kebutuhan industri serta dapat mengembangkan diri sesuai dengan akselerasi perkembangan ilmu pengetahuan dan teknologi.

Berdasarkan uraian di atas, jelaslah bahwa pengelolaan prakerin di Sekolah Menengah Kejuruan di Sukoharjo merupakan program unggulan dalam upaya memberikan bekal ketrampilan dan pengetahuan kepada siswa. Untuk itu dalam penelitian ini akan mengkaji tentang pengelolaan praktik kerja industri di SMK Muhammadiyah 1 Sukoharjo. Fokus penelitian ini adalah bagaimana karakteristik pengelolaan praktik kerja industri di Sekolah Menengah Kejuruan (SMK) Muhammadiyah 1 Sukoharjo.

Tujuan penelitian ini secara teoritis sebagai sumbangan teoritis dalam khasanah pengetahuan terutama proses pembelajaran prakerin di SMK Muhammadiyah 1 Sukoharjo. Secara praktis memberi masukan dan bahan rujukan SMK dalam melakukan bentuk-bentuk kerjasama yang sesuai harapan sekolah dan industri dalam mewujudkan sistem pengelolan Prakerin yang ideal dan efektif.

\section{METODE}

Jenis penelitian ini adalah penelitian kualitatif. Menurut Ibrahim (2015:52) penelitian kualitatif adalah penelitian yang menekankan pada aspek pendalaman data demi mendapatkan kualitas dari hasil suatu penelitian. Teknik pengumpulan data dilakukan pada 
setting alamiah (natural setting) yaitu kondisi yang alamiah, sumber data primer dan teknik pengumpulan data lebih banyak pada observasi berperan serta (participan observation), wawancara mendalam (in depth interview) dan dokumentasi (Sugiyono, 2013:309).

Teknik analisis data yang digunakan dalam penelitian ini adalah teknik analisis data model interaktif menurut Miles dan Huberman yaitu terdiri atas empat tahapan yaitu pengumpulan data, reduksi data, display data dan penarikan kesimpulan. (Ibrahim, 2015:111). Uji keabsahan data dalam penelitian ini menggunakan uji credibility atau kepercayaan terhadap data hasil penelitian dilakukan dengan cara triangulasi.

\section{HASIL DAN PEMBAHASAN}

Hasil penelitian dan pembahasan dalam penelitian ini meliputi: Perencanaan, Pelaksanaan, dan Peniliaan atau evaluasi. Adapun penjelasannya sebagai berikut:

\section{Karakteristik perencanaan praktik kerja industri}

Proses perencanaan dalam pengelolaan prakerin di SMK Muhammadiyah 1 Sukoharjo sudah mengacu dari langkah-langkah perencanaan pembelajaran praktik industri yang meliputi: a) Perumusan tujuan pembelajaran prakerin, b).Pemetaan industri dengan disinkronkan dengan materi sesuai dengan kompetensi yang ada di sekolah,c) Pembekalan praktik kerja industri, d) menentukan alokasi waktu prakerin, dan e) menetapkan guru pembimbing. Dengan demikian perencanaan prakerin di SMK Muhammadiyah 1 Sukoharjo sesuai hasil penelitian dari Hadromi (2015), yang menjelaskan bahwa manajemen praktik di Sekolah Menengah Kejuruan yaitu model momanticproter merupakan studi lanjutan dari perencanaan fungsional manajemen, tindakan, dan evaluasi tentang manusia, uang, metode, material dan aspek waktu produktivitas. yang memiliki implikasi untuk meningkatkan kemampuan manajemen baik keterampilan dan manajerial, bagi siswa, sehingga dapat mengoptimalkan potensi mereka sehingga dapat mendorong kejujuran, tanggung jawab, bekerja keras, dan menghormati orang lain.

Hal ini juga didukung hasil penelitian dari Chan and Chan (2006) yang menyimpulkan bahwa lembaga pendidikan kejuruan harus mempunyai perencanaan jangka panjang, lulusannya akan menjadi pelanggan utama, maka harus membekali mereka dengan pengetahuan dan kecakapan vokasioanal yang dapat membantun mereka dalam menghadapi pasar industri. Lembaga harus mengembangkan model pemikiran untuk membantu para perencana kejuruan dan perencanaan strategis untuk kemakmuran jangka panjang.

Agrawal (2013), dalam penelitian ini juga menjelaskan bahwa sementara disebagian besar negara-negara maju dikawasan Asia, sistem pendidikan dan pelatihan pada SMK telah memainkan peran utama dalam pembangunan ekonomi di kawasan Asia Selatan, khususnya di negara-negara berkembang seperti Afghanistan,Banglades, India dan Pakistan. Pendidikan kejuruan dan sistem pelatihan belumlah sangat sukses. Meskipun pemerintah di negara-negara ini telah membayar secara lebih dengan memperhatikan sektor ini dalam beberapa tahun terakhir, hasil yang masih kurang memuaskan. Sistem pendidikan dan pelatihan pada sekolah kejuruan menghadapu beberapa tantangan; kualitas lembaga dan kurangnya keterkaitan antara pendidikan kejuruan dan penyedia pelatihan dan industri adalah masalah utama.

Kemudian Horn (2014), hasil penelitian ini menyimpulan bahwa pelatihan magang telah dipuji karena efektifitas dalam memperlancar transisi dari sekolah kepada pekerjaan. 
Penelitian ini membandingkan siswa yang magang dengan yang non magang dalam tataran pendidikan dengan menggunakan database besar dan berkarakteristik unik pada tingkat individu yang diamati serta efek tetap pasar tenaga kerja lokal untuk mengendalikan potensi dalam penyeleksian tenaga kerja. Hasil penelitian menunjukan bahwa tidak ada perbedaan yang signifikan dalam peluang kerja antara siswa non magang dalam waktu hanya satu tahun setelah lulus. Meskipun dalam sub sampel kecil dari populasi, perbedaan yang signifikan dapat ditemukan, ini kemungkinan besar karena heterogenitas yang tidak teramati.

Proses perencananan yang dilakukan oleh SMK Muhamadiyah telah sesuai dengan teori perencanaan yang dikemukanan oleh Sudjana (2004:57) perencanaan adalah proses yang sistematis dalam pengambilan keputusan tentang tindakan yang akan dilakukan pada waktu yang akan datang, dan sistematis karena dilaksanakan dengan menggunakan prinsip penggunaan ilmu pengetahuan dan teknik secara ilmiah.

Selanjutnya dalam buku Hand Out pelaksanaan Prakerin Kurikulum 2013, bahwa perencanaan praktik kerja industri yang dilakukan di Sekolah Menengah Kejuruan itu ada beberapa hal, diantaranya: Pemetaan industri yaitu: proses menganalisis Kompetensi Dasar dan topik-topik pembelajaran atau pekerjaan yang ada dalam silabus, dilakukan dengan mempertimbangkan daya dukung sumberdaya yang dimiliki pihak sekolah (SMK) dan pihak Institusi Pasangan (Du/Di). Kemudian menyusun program prakerin sebagai bagian integral dari program pembelajaran perlu memperhatikan kesiapan Institusi Pasangan/Industri dalam melaksanakan pembelajaran kompetensi tersebut. Hal ini dimaksudkan agar dalam pelaksanaannya, penempatan peserta didik tepat sasaran sesuai dengan kompetensi yang akan dipelajari.

Dalam Hand Out kurikulum 2013 dalam perencanaan berikutnya adalah menentukan waktu pelaksanaan yaitu Permendikbud Nomo 60 Tahun 2014 menyatakan bahwa PKL dapat dilaksanakan menggunakan sistem blok selama setengah semester (sekitar 3 bulan); dapat pula dengan cara masuk 3 hari dalam seminggu, setiap hari 8 jam selama 1 semester.

Praktik kerja industri adalah suatu cara menyelenggarakan pendidikan dan pelatihan kejuruan khususnya pada Sekolah Menengah Kejuruan (SMK) yang memadukan kegiatan belajar di sekolah dan kegiatan belajar di temapat industri sesungguhnya dan relevan di lapangan kerja atau dunia industri. Agar pengelolan prakerin menjadi bagian organisasi yang dapat menyiapkan tenaga kerja terampil dan mempunyai daya saing, maka Prakerin perlu di kelola dengan baik dan profesional. Hal ini sejalan dengan Peraturan Pemerintah Nomor:1489/U/1992, yaitu menyiapkan siswa untuk memasuki lapangan kerja dan mengembangkan sikap profesional.

Perencanaan Prakerin di SMK Muhammadiyah 1 Sukoharjo juga sudah sesuai dengan hand out kurikulum 2013, yaitu melakukan pemetaan industri, menyusun program prakerin sampai proses evaluasi yang integral dari program pembelajaran di Sekolah yang disesuaikan dengan pembelajaran di industri.

\section{Karakteristik pelaksanaan praktik kerja industri}

Pelaksanaan Praktik Kerja Industri di SMK Muhammadiyah 1 Sukoharjo meliputi: a) Pengorganisasian yang sesuai dengan struktur organisasi yang di tetapkan oleh sekolah, yang dilakukan untuk menghimpun dan mengatur semua sumber-sumber yang diperlukan, 
sehingga rencana yang telah dibuat dapat dilaksanakan dengan lancar dari awal sampai akhir. b) Penentuan waktu prakerin di SMK Muhammadiyah 1 Sukoharjo sudah ditetapkan dengan sistem "block release".c). Kegiatan penyerahan siswa ke Du/Di dilaksanakan dengan dua metode yaitu, untuk siswa prakerin yang terjangkau maka akan langsung diantar oleh tim Pokja Prakerin dan diserahkan ke pihak industri sedangkan untuk siswa yang prakerin di luar kota untuk proses penyerahan ini dilakukan media komunikasi via telpon atau faxmile. d).Pelaksanaan monitoring siswa prakerin dilaksanakan dalam satu periode adalah 3 (tiga) kali yang meliputi saat penyerahan awal, monitoring disaat proses pelaksanaan dan akhir saat penarikan. e). Pembimbingan hasil laporan prakerin: dimulai dengan sosialiasi daftar nama pembimbing prakerin, batas waktu pembimbingan dan waktu pengujian hasil prakerin, kemudian untuk format penyusunan laporan prakerin mengaju pada buku panduan prakerin.

Pelaksanaaan praktik kerja industri di SMK Muhammadiyah 1 Sukoharjo, juga sesuai dengan hasil penelitian Schermerhorn (2008:13), yang menyatakan bahwa pelaksanaan merupakan proses pemberian tugas, pengalokasian sumber daya serta pengaturan kegiatan secara terkooordinir kepada individu dan kelompok untuk menerapkan rencana. Dan juga sependapat dengan hasil penelitian Anita Sui ManLeung (2010), hasil penelitian ini menyatakan bahwa pendidikan kejuruan yang ditawarkan di salah satu institusi di Hong Kong dapat menjadi peluang pengembangan pribadi yang mendukung pengembangan keterampilan yang berguna untuk pengembangan pribadi yang lebih luas.. Strategi pembelajaran yang lebih inovatif dalam penelitian ini menawarkan panduan praktis mengenai pengembangan pribadi untuk pendidik, dan merumuskan model pembelajaran aktif untuk mendukung pengembangan siswa di sekolah kejuruan.

Pelaksanaan Prakerin ini juga mendukung hasil penelitian Aktaruzzaman and Clement, (2011), yang menyimpulkan bahwa dengan meningkatkannya globalisasi dan liberalisasi disebagian besar negara di seluruh dunia, realisasi tantangan yang dihadapi untuk membuat pendidikan dan pelatihan (VET) kejuruan sistem menjadi lebih berbasis kebutuhan dan efektif, lebih dinamis dan responsif terhadap perubahan yang terjadi di skenario industri. Para lulusan yang keluar dari lembaga VET harus lebih mampu kinerja yang baik. Oleh karena itu, sistem VET harus merespon kebutuhan teknologi yang berubah dengan cepat dunia kerja dengan terus mengevaluasi dan memodifikasi kurikulum, memperkenalkan program baru, pendidikan guru kejuruan, modernisasi laboratorium dan lokakarya melalui kemitraan yang erat antara lembaga VET dan dunia kerja.Oleh karena itu reformasi yang signifikan perlu dibuat dalam domain yang lebih baik beradaptasi pendidikan guru kejuruan dan sistem VET terstruktur dengan baik dan memiliki dampak langsung untuk meningkatkan daya saing ketrampilan tenaga kerja untuk pasar tenaga kerja, produktifitas dan untuk mempromosikan kegiatan kewirausahaan.

Keberhasilan Pelaksanaan Praktik kerja industri (Prakerin) di SMK Muhammadiyah 1 Sukoharjo tidak lepas dari peran kepala sekolah. Sebagai manajer kepala sekolah harus mampu mengkondisikan bawahan, menciptakan iklim organisasi yang baik, komunikasi yang efektif ,sehingga dalam melaksankan program sistem ganda (PSG) yang implemtasinya berupa Prakerin bisa mendapatkan Institusi pasangan yang sesuai dengan program keahlian sehingga para siswa/peserta didik setelah lulus dapat diterima dilapangan pekerjaan sesuai dengan harapan sekolah. 


\section{Karakteristik Penilaian Praktik Kerja Industri}

Penilaian praktik kerja industri yang dilakukan SMK Muhammadiyah 1 Sukoharjo, adalah dilakukan dengan dua tahap yaitu oleh pembimbing industri dan pembimbing sekolah, dengan menggunakan format penilaian kolektif (NK) dari lembar penilaian secara kolektif dari kegiatan siswa selama mengikuti praktik industri, sekaligus sebagai bahan untuk pengisian surat keterangan praktik kerja industri.yang ditulis dengan angka dan huruf, dengan batas nominal sebagai berikut : 86 s.d. $100=\mathrm{A}$ (memuaskan), 71 s.d. $85=\mathrm{B}$ (baik),56 s.d. 70 $=\mathrm{C}$ (cukup),31 s.d. 55= D (kurang). Penilaian total siswa prakerin dinilai dengan parameter nilai dari industri/ sertifikat prakerin (IN) diberi bobot $60 \%$, nilai jurnal prakerin (JP) diberi bobot $10 \%$, nilai ujian lisan (UL) diberi bobot $20 \%$, dan nilai karya tulis/laporan (LP) diberi bobot $10 \%$. Sehingga nilai akhir prakerin adalah : 0,6 (IN) + 0,1(JP) + 0,2 (LP) +0,1 (LP).

Penyelenggaran progam prakerin dengan diakhiri dengan proses penilaian ini juga mendukung hasil penelitian Nelson Ander, (2010), yang menyimpulkan bahwa pendidikan vokasi merupakan pendidikan dan pelatihan yang diharapkan mampu untuk menyediakan tenaga kerja yang relevan dengan dunia usaha. Dengan keterserapan tenaga kerja pada perusahaan akan menunjang pada produktifitas, meningkatkan pertumbuhan ekonomi dan meningkatkan daya saing. Dengan demikian pendidikan kejuruan mempunyai tujuan untuk menyediakan individu dengan ketrampilan yang lebih yang langsung diterapkan di tempat kerja. Dalam konteks ini, pendidikan kejuruan mempunyai kepentingan tertentu karena dan alasan untuk percaya bahwa pendidikan kejuruan itu lebih unggul dari pendidikan umum dari sudut pandang bersosialisasi, serta dalam mempromosikan akses ke pasar kerja.

Penilaian praktik kerja industri yang dilakukan di SMK Muhammadiyah 1 Sukoharjo telah sesuai dengan teori penilaian yang dikemukanan oleh Sudjana ( 2004:247), bahwa penilaian (evaluating) adalah suatu kegiatan yang dilaksanakan untuk mengetahui apakah tujuan yang telah ditentukan dapat dicapai, apakah pelaksanaan program sesuai dengan rencana, dan atau dampak apa yang terjadi setelah program dilaksanakan. Karena prakerin merupakan program bersama antara sekolah dengan pihak DU/DI, maka masalah evaluasi dalam prakerin perlu dibicarakan bersama. Namun demikian pelaksanaan evaluasi terhadap proses belajar siswa di DU/DI sepenuhnya harus dilakukan oleh pihak DU/DI dan evaluasi kegiatan siswa di sekolah dilaksanakan oleh pihak sekolah.

\section{PENUTUP}

Perencanaan Praktik kerja indsutri (Prakerin) disusun secara matang dan terprogram dan sudah dibukukan dalam bentuk buku panduan prakerin yang diawali disosialisasikan kepada warga sekolah dan segenap pihak yang berkepentingan. Perencanaan Prakerin di SMK Muhammdiyah 1 Sukoharjo memperhatikan faktor-faktor sebagai berikut: 1).pemetaan industri, 2). menyusun program prakerin, 3) waktu pelaksanaan prakerin,4).pembekalan prakerin.

Pelaksanaan Prakerin di SMK Muhammadiyah 1 Sukoharjo berorientasi pada standar kompetensi yang dibutuhkan oleh industri dengan dibuktikan sertifikat yang ditanda tangani oleh pihak sekolah dan pihak industri. Pelaksanaan Prakerin di SMK Muhammadiyah 1 Sukoharjo meliputi: 1). Pengorganisasian yang tertuang dalam Struktur Organisasi Prakerin, 2). Penyerahan siswa prakerin ke Industri, 3).monitoring, dan 4). Penarikan siswa prakerin 
ke Sekolah.

Penilaian atau evaluasi prakerin di SMK Muhammadiyah 1 Sukoharjo terbagi dalam dua tahap, yaitu 1). penilaian dilakukan oleh pembimbing Industri yang meliputi penilaian: penilaian kehadiaran, kemampuan bekerja, tanggungjawab, insiatif, kerjasama, loyalitas, sikap, kejujuran, prestasi kerja, 2). penilaian dari pembimbing Sekolah yang meliputi: penilaian jurnal prakerin,penilaian laporan prakerin, dan penilaian ujian lesan. Kemudian dari aspek penilaian ini digabungan menjadi satu dengan parameter nilai dari industri/ sertifikat prakerin (IN) diberi bobot $60 \%$, nilai jurnal prakerin (JP) diberi bobot $10 \%$, nilai ujian lisan (UL) diberi bobot $20 \%$, dan nilai karya tulis/laporan (LP) diberi bobot $10 \%$. Sehingga nilai akhir prakerin adalah : 0,6 (IN) + 0,1(JP) + 0,2 (LP) +0,1 (LP).

Penyelenggaraan Praktik kerja industri di SMK Muhammadiyah 1 Sukoharjo agar dapat dikelola secara efektif, maka peneliti sampaikan saran-saran sebagai berikut: 1). Perencanaan program prakerin khususnya pemetaan industri harus dilakukan besama-sama antara pihak sekolah dengan industri terutama terkait masalah penjadwalan, kesesuaian kompetensi produktif di Sekolah dengan kompetensi kerja di Industri, standar operasional prosedur, pemantauan, dan pengawasan serta evaluasi hasil prakerin, 2). frekuensi monitoring Prakerin ke industri/perusahaan perlu ditingkatkan, 3).Pihak sekolah harus tetap menjaga keharmonisan dengan pihak industri dalam rangka melaksanakan bentuk-bentuk kerjasama yang saling menguntungkan sesuai dengan kebijakan Link and Macth yang sudah menjadi program Kementrian Pendidikan Nasional, 4). Pihak industri hendaknya lebih terbuka lagi dalam menerima prakerin, baik menyangkut jumlah peserta ataupun waktu pelaksanaannya, 5).Pemerintah daerah khususnya Dinas Tenaga Kerja, Dinas Pendidikan atau Dinas terkait lainya harus bersinerji dalam menyusun kebijakan Sekolah Menengah Kejuruan dan pengembangannya serta penempatan lulusan SMK di daerah.

\section{DAFTAR PUSTAKA}

Agrawal Tushar, (2013), Vocational Education and Training Program (VET): An Asian Perspective. Asia-Pacific Journal of Cooperative Education,2013, 14(1),15-26.India : Indira Gandhi Institute of Development Research ( IGDR).

Akturuzzaman, Md and Clement, Che Kum, (2011), .Vocational Education and Training ( VET) in Human Resource Development : A Case Study of Bangladesh, Academic Researc Internasional, Vol.1, No.7, Tahun 2011, P.266-275.

Anita Sui Man Leung (2010). An Effective Learning Model to Support People Development: The Emerging Approach of The Hong Kong Institute for Vocational Education.. Department of Business Administration Hong Kong Institute of Vocational Education (Tsing Yi)

Axel Göhringer (2002). The Dual System of Higher Education in Germany University of Cooperative Education Asia-Pacific Journal of Cooperative Education .

Direktorat Pembinaan sekolah Menengah kejuruan (2015), Hand Out Praktik Kerja Lapangan (Prakerin) pada Implementasi Kurikulum 2013, Direktorat Jenderal Manajemen Pendidikan Dasar dan Menengah, Departemen Pendidikan Nasional

Departemen Pendidikan dan Kebudayaan (1993), Sistem Ganda pada Pendidikan Menengah Kejuruan . Depadikbud. Jakarta. 
Deal, Debby: C Stephen White.2006. Voices From The Classroom: Literacy Beliefs and Practices of Two Novice Elementary Teachers. Journal of Research in Childhood Education. Olney

Kuswana, Wowo Sunaryo 2013. Dasar-dasar Pendidikan Vokasi dan Kejuruan. Cetakan ke-1. Bandung. Alfabeta.

Kamajaya. Praktik Kerja Industri (Prakerin),// kamajaya65.blogspot.com. Selasa 03 Nopember 2009.diakses 30-10-2015.

Mufadi Al- Momani (2012). Teachers Implementation of Effective Classroom Management from Vocational Education Students' Perspectives . 1Dept. of Applied Science, AlBalq'a' Applied University.Jordan

Nolker, H. Dan Schonfeld,E (1983).Pendidikan Kejuruan. Jakarta. Gramedia.

Fatah, Nanang 2013. Landasan Manajemen Pendidikan. Bandung .PT. Remaja Rosdakarya Offset.

Hadromi, Maman Rachman, Soesanto \& Tri Jaka Kartana (2015). The Development of Productivity Practical Management Model at Automotive Mechanical Technology Skill Program in Semarang Vocational Schools, Indonesia International Education Studies; Vol. 8, No. 5; 2015 ISSN 1913-9020 E-ISSN 1913-9039

Horn, Daniel, (2014). The Effectiveneess of Apprenticeship Training a within tract comparison of workplace-based and school based vocational training in Hungary. Budapest Working Papers on the labour Market. 2014, 11(5) 5.Hungarian: Hungarian Academy of Sciences, Deparment of Human Resource, Corvinus University of Budapest.

Ibrahim (2015). Metodologi Penelitian Kualitatif-Panduan Penelitian beserta contoh Proposal Kualitatif. Cetakan ke-1 Bandung .Alfabeta

Peraturan Menteri Pendidikan Nasional Nomor 19 tahun 2007. tentang Standar Pengelolaan Pendidikan.

Sutama, (2015), Metode Penelitian Pendidikan Kuantitatif, Kualitatif, PTK dan $R \& D$, Fairus Media, Gumpang Kartosuro

Sugiyono, (2013), Metode Penelitian Kuantitatif, kualitatif dan RD, cetakan ke delapan belas, Alfabeta, Bandung

Ridhotullah, S. (2015). "Pengantar Manajemen”. Cetakan pertama, Prestasi PutakaryaJakarta. Indonesia.

Undang-undang Republik Indonesia Nomor 20 tahun 2003. Tentang : Sistem Pendidikan Nasional . Jakarta: Sinar Grafika

Wena,M. (1996). Pendidikan Sistem Ganda . Bandung : Tarsito. 